\title{
Estrategia comunicacional para el "Preescolar Arlen Siú"
}

\author{
Bra. Ana Guadalupe Padilla Sánchez. \\ Facultad de Humanidades y Ciencias Jurídicas. ${ }^{1}$
}

Recibido 24 abril 2013- Aprobado 28 de octubre 2013.

\section{RESUMEN}

El objetivo de esta investigación es la elaboración de una estrategia de comunicación para poder facilitar el flujo comunicacional en el preescolar Arlen Siú. Se realizó un diagnóstico en el centro en el cual se reflejara la realidad comunicacional que existe en el centro educativo. La falta de estrategias claras de comunicación interna, externa e interinstitucional, retrasa los procesos y obstruye la abstención de una mejor organización y esto repercute de manera negativa en el preescolar Arlen Siú. Esta investigación se ubica en la clasificación exploratoria, porque no se había realizado un proceso de investigación sobre la situación de comunicación institucional que aportase a la construcción y validación de una estrategia comunicacional.

Palabras clave: preescolar, flujo comunicacional, estrategias, centro educativo.

\section{INTRODUCCIÓN}

El Preescolar Arlen Siú fue creado hace 21 años con el fin de disminuirlas necesidades de los trabajadores de la Universidad Nacional Autónoma de Nicaragua, ya que una gran parte del personal administrativo de la universidad tiene hijos pequeños y por su trabajo no podían brindarles la atención necesaria. El presente trabajo "Estrategia comunicacional para el preescolar Arlen Siú" tiene como objetivo la elaboración de una estrategia de comunicación para poder facilitar las herramientas necesarias con las que se pueda solucionar los posibles obstáculos existentes en el flujo comunicacional. Para ello se realizó un diagnóstico en el centro que presentara las realidades comunicacionales existentes en el centro educativo, como parte de un estudio sobre el funcionamiento de la comunicación institucional de la UNANManagua.

La falta de estrategias claras de comunicación interna, externa e interinstitucional, retrasa los procesos y obstruye la abstención de una mejor organización y esto repercute de manera negativa en el preescolar Arlen Siú. Para empezar, esta fase del estudio indica que esta investigación se ubica en la clasificación exploratoria, en el Preescolar Arlen Siú no se había realizado un proceso de investigación sobre la situación de comunicación institucional que aportase a la construcción y validación de una estrategia comunicacional.

En dicho Centro escolar, se han hecho estudios pedagógicos, en su gran mayoría son estudiantes de las carreras de Educación e Idiomas quienes realizan prácticas o trabajos investigativos, que han dejado resultados y aportes positivos para la institución. ¿Existe o no una comunicación fluida entre las diferentes áreas de trabajo del preescolar Arlen Siú que armonice el entorno laboral interno, externo e interinstitucional del centro?

\footnotetext{
${ }^{11}$ Trabajo dirigido por la maestra Lesbia Bermúdez
} 


\section{MATERIALES Y MÉTODOS}

La realización de esta estrategia comunicacional es con el fin de identificar las necesidades y desempeño de la comunicación interna, externa e interinstitucional del preescolar Arlen Siú, la información que aquí se presenta es de carácter descriptivo el propósito es que mediante estrategias de observación y trabajo de campo se logre alcanzar el objetivo del análisis comunicacional en otros términos la investigación se enmarca en la descripción e interpretación sobre el proceso de comunicación. Para la recopilación de información sobre el Preescolar se utilizaron los métodos cualitativos y cuantitativos dentro de los primeros se tiene el cuaderno de campo donde se hicieron las debidas anotaciones del lugar, se hizo uso la encuesta, grupo focal y no se puede obviar la observación, que forma un pilar indispensable en el proceso de elaboración de la estrategia.

Para la realización de un buen diagnóstico es necesario realizar una observación general y ésta se dio a través de visitas in situ para hacer un reconocimiento de la situación comunicacional, atención, desarrollo laboral, condiciones de la infraestructura etc. Los datos cuantitativos fueron el número de personas encuestadas, en este caso fueron 80 padres de familia y diez docentes, con el objetivo de tener una percepción y crear un criterio sobre la comunicación interna, externa e interinstitucional.

\section{RESULTADOS}

\section{Diagnóstico sobre las realidades comunicacionales existentes en el centro educativo}

La comunicación entre los padres de Familia y el personal Docente, el 88, 75\% de la población encuestada estuvo de acuerdo que sí hay comunicación y sólo el 11, 25\% dijo que no hay comunicación. Este porcentaje refleja que los padres no asisten mucho al Preescolar, puesto que mandan a sus hijos en recorridos escolares. En la interrogante de, quién le informa sobre las actividades que se realizan en el centro educativo el $91.25 \%$ de los encuestados señalaron que son las docentes quienes le informan, y un $8.75 \%$ señaló que la Dirección.

A la interrogante de cómo valoran la comunicación de la Dirección del Preescolar Arlen Siú con respecto a las actividades, el $41.25 \%$ la calificó de excelente, $53.75 \%$ de muy buena, un $5.5 \%$ de regular. En cuanto a la comunicación entre Dirección y padre de familia los datos son los siguientes: $47.5 \%$ la calificó de muy buena; un $40 \%$ de excelente y un $12.5 \%$ de regular. Los padres de familia manifestaron que la comunicación que ellos logran ver en es muy buena, no es excelente porque todos somos humanos y en algún momento nos equivocamos. La Directora toma decisiones rápidamente y le informa directamente a los padres y luego a los docentes, por lo general esto ocurre cuando se hacen actividades inesperadas.

En cuanto a la comunicación entre todo el personal que la labora en el centro, los padres opinaron: el $71.25 \%$ señaló que hay buena comunicación, este porcentaje los padres lo notan porque todo el personal se organiza muy bien al momento de las actividades, también cuando atienden a los pequeños, esto demuestra una vez más las buenas relaciones laborales que hay en el centro educativo; un $3.75 \%$ dijo que no y un $25 \%$ señaló que no sabe si hay comunicación.

La comunicación entre el personal docente fue calificada por las docentes encuestadas de excelente. Esto se debe a que constantemente se hacen reuniones entre Dirección y personal docente. Un 30\% de las encuestadas no la calificó de excelente pero sí señaló que es muy buena porque en general la información es fluida, el otro $30 \%$ dijo que es buena. La comunicación juega un papel fundamental dentro del centro y vimos que sí existe comunicación entre el personal docente y la Directora.

La siguiente pregunta, cómo califica las relaciones entre el personal Docente y la Dirección, arrojó los siguientes datos; el $70 \%$ de las docentes encuestadas calificó de muy buena las relaciones que existen 
entre el personal docente y la Dirección. Un 30\% la calificó como excelente puesto que la Directora tiene buenas relaciones humanas con las personas que la rodean.

El 60\% señala que hay suficiente divulgación de información en el Preescolar Arlen Siú, dado que constantemente están publicando en los murales informativos todo lo que sucede en el centro educativo y el $40 \%$ opinó que no hay suficiente divulgación, quizás puede ser porque no ven viable los canales por los que informan las actividades. El 70\% de las docentes encuestados señalaron que el medio que más utilizan para difundir sus planes de estudio son los boletines informativos, la dirección trata de repartirlos entre el personal que labora en la universidad y sólo un 30\% manifestó que eran por otros medios como los brochure.

Hay comunicación entre la Facultad de Educación e Idiomas, la Dirección y el personal Docente El 70\% de los encuestados manifestó que si hay comunicación entre las tres entidades y el $30 \%$ dice que esa comunicación no es tan fluida. No existe la comunicación interpersonal, pero sí se les brindan orientaciones por parte de la Facultad a través de la dirección con quien sí están en constante comunicación.

Los resultados de la siguiente pregunta, cuáles son los canales de comunicación que utiliza el preescolar para informar, fue el siguiente; un $100 \%$ de las encuestadas señaló que el medio que utiliza el preescolar para comunicar e informar cualquier tipo de actividades que se realicen en el centro son las circulares. La comunicación en el Arlen Siú se maneja de manera ordenada y bastante fluida por medios escritos, ya que se puede considerar la forma más segura de comunicarse. Sin embargo, hay una limitante en cuanto a los medios de comunicación empleados en el Centro, pues en ocasiones las circulares no tienen eficacia.

\section{Estrategia comunicacional para el preescolar de aplicaciones Arlen Siú.}

Con el objetivo de conocer a fondo cómo es la comunicación del Preescolar tanto a nivel interno, externo e interinstitucional se elaboró esta estrategia comunicacional. Esto con el propósito de consolidar las relaciones que tienen con el Ministerio de Educación para que las docentes del Preescolar Arlen Siú obtengan mayor experiencia con respecto al ámbito pedagógico. También se pueden organizar capacitaciones con los docentes del área de Pedagogía de la UNAN-Managua donde ellos puedan aportar ideas para que las docentes del centro obtengan mayor experiencia y estén actualizadas.

Realizar encuentros entre la Directora del centro y las Docentes para la planificación eficaz de los trabajos del centro. Además, elaborar pancartas donde se informe de las actividades que el Preescolar realiza, hablar con los padres de familia para obtener un apoyo y participación en dichas actividades.

Realizar gestiones con la Decanatura para la elaboración de un banner publicitario donde se ponga la insignia del Preescolar en las a fueras del centro de estudios para que sea identificado por las personas que pasan a diario por esa vía.

Crear un espacio en la página Web oficial de la Universidad para dar a conocer cómo funciona el centro y cuál es el origen de su creación. Esto se puede lograr haciendo convenios con la carrera de Computación para que los alumnos que hagan prácticas creen un espacio o una página oficial del centro (Preescolar Arlen Siú),donde se pueda divulgar toda la información necesaria, a la vez se puede hacer uso de las otras redes sociales como el Facebook, blog, etc.

Promover reuniones entre (Docentes, personal administrativo y Directora) donde se fomente el sentido de pertenencia en todos los trabajadores del centro, adaptándose y apropiándose de las reglas laborales, 
mensajes institucionales y todo tipo de información acerca del Preescolar. Además, crear espacios comunicacionales directos entre docentes, padres de familia, personal administrativo como reuniones, charlas o bien grupos focales donde se puedan debatir de forma general los diferentes problemas o necesidades que surjan en el centro de aplicaciones Preescolar Arlen Siú para así obtener mejores resultados en todos los ámbitos del centro.

La Decanatura debe promover reuniones cada semestre con todo el personal que labora en el centro para brindarle la información necesaria del trabajo que hace esta Facultad e informar sobre los logros obtenidos en el transcurso de cada semestre asimismo, hacer un plan de trabajo en las que involucre al centro y a la Decanatura para fortalecer la comunicación.

Promover y realizar talleres de relaciones humanas entre todo el personal que labora en el Preescolar Arlen Siú para poner en práctica los valores que cada trabajador debe de tener al momento de realizar su trabajo como la solidaridad, la ética, el compañerismo y el respeto. Se puede hacer un acuerdo con el Ministerio de Educación para que ellos envíen a especialistas en el tema y así poder compartir experiencias entre ambas instituciones.

\section{CONCLUSIONES}

Al hacer esta planificación participativa nos facilitó la detección de algunos puntos que deben fortalecerse dentro de la comunicación interna, entre las cuales destaca el hecho de que existe desinformación en cuanto las actividades y derechos de los trabajadores.

Elaboración de una propuesta de misión, visión y valores que no poseía el lugar todas estas propuestas están basadas en las necesidades y debilidades que posee dicho centro educativo.

\section{BIBLIOGRAFÍA}

Conceptos de comunicación (2005,4 de febrero) http://es.wkipedia.org/wiki/comunicacion.

Rueda, H, Blandón,I, (5 de octubre 2012). Estrategia comunicacional del periódico "EL FILCOM" Jiménez, (1982) ¿Qué es la comunicación? Comunicación y ámbitos.

Teoría de organizaciones (2008,30de enero). Consultado en www.getiopolis.con/recursos/documentos/fulldocs/ger/teorgapuuch.http 